\title{
LETTERS
}

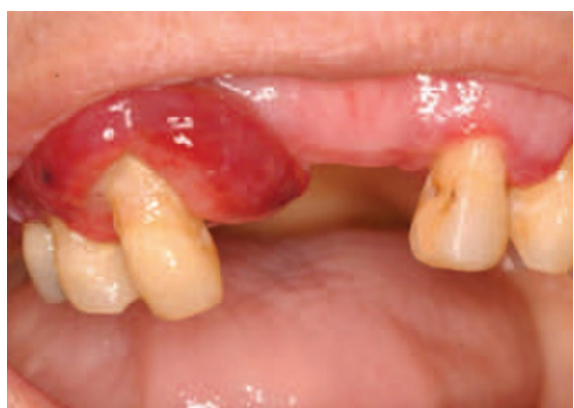

Fig. 1 The swollen gingiva

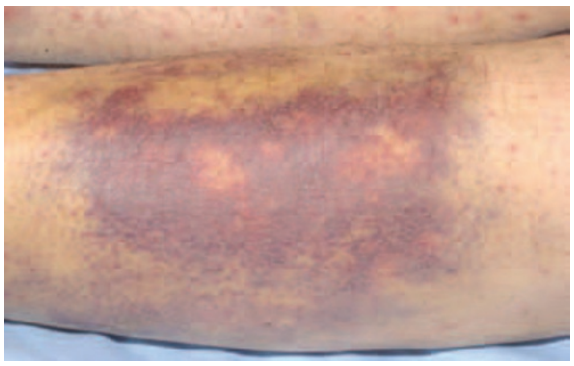

Fig. 2 Dependent oedema of the lower legs

was made. The patient was admitted for further investigations and vitamin C supplementation was commenced. No other intervention was needed. At a four week review weight had been gained and only mild gingival inflammation secondary to her underlying periodontal disease was present.

As the UK's population is ageing, with increasing numbers residing in care homes, we feel it is important for clinicians to be aware that scurvy could be affecting our patients and particularly those who may be visited on a domiciliary basis.

$$
\begin{array}{r}
\text { J-M. Chapman, J. J. Marley } \\
\text { Belfast }
\end{array}
$$

1. Care Quality Commission. Dignity and nutrition inspection programme: national overview. October 2011. Available at: http://www.cqc.org.uk/_db/_ documents/20111007_Dignity_and_nutrition_ inspection_report_FINAL.pdf.

2. Hirschmann J V, Raugi G J. Adult scurvy. J Am Acad Dermatol 1999; 41: 895-909.

3. Richardson T I L, Ball L, Rosenfeld T. Will an orange a day keep the doctor away? Postgrad Med J 2002; 78: 292-294.

4. Halligan T J, Russell N G, Dunn W J, Caldroney S J, Skelton T B. Identification and treatment of scurvy: a case report. Oral Surg Oral Med Oral Pathol Oral Radiol Endod 2005; 100: 688-692.

DOI: 10.1038/sj.bdj.2011.1061

\section{INWARD DENTAL TOURISM}

Sir, dental tourism has been a controversial subject in the UK in recent years. Although statistics for the number of UK residents travelling overseas for dental treatment are not officially collated, media reports have suggested that an increasing number of individuals are pursuing this option. That impression has been echoed by the BDA's own research, which has identified a significant number of patients travelling to countries including Hungary and Poland for procedures, and needing attention for complications after returning to the UK.

That need for after care and the concerns it raises have left UK dentists lamenting the choices individuals have made and the BDA has consistently warned patients to think very carefully before deciding to go overseas. But it's not just practitioners in the UK who have reservations about UK citizens going overseas for care. Members of the BDA's Middlesex and Hertfordshire Branch, on a recent trip to Budapest, heard from Dr Jolán Bánóczy, Professor Emeritus at the Department of Oral Biology, Semmelweiss University of Medicine in Budapest, how homegrown Hungarian dentists view inward dental tourism in their country. Dr Bánóczy discussed dental tourism at some length, which aroused a good deal of interest from the audience. She personally did not agree with it, as after care is usually impossible. Dentists in Hungary obviously share the reservations of colleagues in the UK about dental tourism. The Hungarian Dental Association will give no opinion on the matter, but the government is in favour because it brings much-needed foreign currency into the country.

Dr Bánóczy also highlighted the possibility of dentistry becoming more commercial if the number of overseas visitors continues to increase, being concerned that if Hungarian dentists are concentrating on treating patients from overseas, there may be an adverse impact on oral health provision for the Hungarian population. Although Hungary has four dental schools producing in the region of 220 graduates a year, the oral health challenges they present are significant and Dr Bánóczy explained that Hungary faces high rates of decay in rural areas, is one of the worst countries for rates of mouth cancer and must face the same demographic challenge as the UK: an ageing population.
Witnessing wise words on an international stage provided Branch members with food for thought.

\section{B. Arends}

By email

DOI: 10.1038/sj.bdj.2011.1062

\section{UPDATED RESOURCE FOR DRUG PRESCRIBING}

Sir, I would like to draw your readers' attention to the second edition of Drug prescribing for dentistry, a publication by the Scottish Dental Clinical Effectiveness Programme (SDCEP). Released in August 2011, this resource has been written by a small group of clinicians with a particular interest in prescribing.

Specifically applicable to primary care dental professionals, it provides fully updated guidance, presented in a user-friendly, ring-binder format. The updated edition improves on its predecessor by a new divider-style design separating the ten chapters to allow ease of navigation. Extra sections on adverse drug reactions and labelling are incorporated along with more detailed information on the treatment of medical emergencies in dental practice to include milder forms of allergy, acute coronary syndromes, and stroke. Also included is a useful section on recommendations for self audit to improve the quality of drug prescribing in dentistry.

Designed to be a handy resource to be used in conjunction with the British National Formulary (which contains the Dental Practitioners Formulary), information has been collated from the BNF (BNF 61), BNF for Children (BNFC 2011), and a wide variety of clinical and product literature including guidance from professional bodies.

Although it is a Scottish publication, this guidance is also available electronically via the SDCEP website http:// www.sdcep.org.uk/index.aspx?o=2334 and plans are in hand to develop a Smartphone app.

\section{N. E. O'Murchu} Glasgow 